\title{
Parametric Analysis for Multiple Anchor in Steel-To- Concrete Connection Subjected to Moment and Shear Loading
}

\author{
Pingping Guan ${ }^{1}$, Qun Xie ${ }^{1}$ and Sichao Yang ${ }^{2}$ \\ ${ }^{1}$ School of civil engineering and architecture, University of Jinan, 250022, Jinan China \\ ${ }^{2}$ Shandong huadu architectural design institute, Co., Ltd, 250000 Jinan China
}

\begin{abstract}
ABAQUS software had been employed to analyze the performance of steel-to-concrete connections with post-installed adhesive anchor, which subjected to combined bending moment and shear loads. The study focused on the effect of spacing and edge distance of anchors on anchorage behavior. Analysis results indicated that independent concrete cones appeared in the case of spacing 12d. Overlapped concrete cone occurred in final failure when spacing is $5 \mathrm{~d}$ and $8 \mathrm{~d}$. Based on the analysis of edge distance, the anchorage strength had significant reduction because of the inadequate concrete load-bearing area in edge distance $5 \mathrm{~d}$. With the increase of edge distance, there was enough concrete area to resist and transfer the applied load, and the whole concrete cone would be within concrete base which guarantees to form independent concrete cone. At last critical value $8 \mathrm{~d}$ of edge distance was suggested in order to fully develop anchor steel strength.
\end{abstract}

Keywords-multiple anchors ; steel-to-concrete; numerical analysis; edge distance; spacing

\section{INTRODUCTION}

As a reliable and economical fastener, adhesive anchor had been widely used in engineering application where a structural steel was intended to connect with an existing concrete element. Currently many researchers had investigated the effect of parameters such as embedment depth, anchor size, concrete strength, temperature and humidity on tensile behavior of single anchor. However in most applications anchors often worked in group and probably were subjected to combined action of bending moment and shear loads and for multipleanchor more attention should be paid on the impact of spacing and edge distance on strength and failure mode [3, 4].Little knowledge about anchor group under combination loading was available currently. For the purpose of better understanding the behavior of anchor groups under combination loading, ABAQUS software was employed and a serial of 3D models were established to investigate the influence of variable parameters.

\section{RESEARCH BACKGROUND}

\section{A. Domestic Research}

Dr. Shu-guang Zhang used the FE software to analyze the effect of edge distance on performance of double anchors [4]. Dr. Zhou-dao $\mathrm{Lu}$ had conducted extensive research on the effect of spacing and edge distance of post-installed anchor group in shear performance. The results indicated that concrete failure occurs when the edge distance was small while anchors failure in the case of enough edge distance. Anchor design method for shear strength was proposed [1-3]. Xin-lin Wang studied experimentally and numerically the relationship between the distance and bearing capacity of the chemical anchor group and mainly analyzed the strength decrease for anchor system when the anchor spacing was less than the value recommended by related codes. Tie-zhu Jiang conducted the tensile test of single anchor, double anchors as well as four anchors respectively, and found out the failure mode of anchor group in tensile [6].

\section{B. International Research}

Yi-jun Li employed finite element method to study the tensile performance of four anchors and put forward the concept of group effect [7]. Dieter Lotze studied experimentally the static behavior of anchors with small edge distance and the result showed that the anchor could not develop its full strength if the distance between applied load and anchor surface was small[8]. Yong-Gang Zhang (2001) studied experimentally the seismic performance of group anchors for undercut anchor and expansion anchor under combined moment and shear loading. Compared with static data, the anchor strength in dynamic test had no significant decrease with more ultimate displacement [9]. Cook discovered that the load bearing capacity would have $15 \%$ drop than that of the single anchor when the spacing of anchors was less than $200 \mathrm{~mm}$ and proposed that diameter and concrete cone depth would be influenced by anchor spacing [10].Jennifer had carried out study on the tensile performance of four anchors with $16 \mathrm{~mm}$ diameter and the experimental result showed that the concrete cone failure occurred in spacing 8d and interfacial bond failure happened in spacing $10 \mathrm{~d}$. At last it was recommended to take a minimum value of $5 \mathrm{~d}$ for edge distance and $10 \mathrm{~d}$ for spacing [11].

\section{MODEL DETAILS}

The model was composed by I-shaped steel beam, reinforced concrete block, adhesive anchors and steel plate to form a steel-to-concrete connection, the steel beam had been designed with sufficient strength to ensure anchorage failure instead of element failure. The dimensions of steel beam and 
reinforced concrete block were kept to be constants in all models. The vertical distance between the top anchors and the bottom anchors was kept as a constant of $190 \mathrm{~mm}$. The Ishaped steel beam was $800 \mathrm{~mm}$ in length and the dimension of section was $400 \mathrm{~mm} \times 300 \mathrm{~mm} \times 8 \mathrm{~mm} \times 12 \mathrm{~mm}$. The dimension of concrete base was height $800 \mathrm{~mm}$ x width $360 \mathrm{mmx}$ depth $210 \mathrm{~mm}$. The diameter of anchor was $12 \mathrm{~mm}$ and the total length was $210 \mathrm{~mm}$ for embedment depth was $180 \mathrm{~mm}$ (15d). The steel plate's thickness for all models was $20 \mathrm{~mm}$ which could avoid unexpected failure. The elastic modulus and yield strength of steal was $2.1 \mathrm{x} 105 \mathrm{MPa}$ and $235 \mathrm{MPa}$ respectively. For concrete property, damage-plastic model had been chosen and the strength grade was C30 with elastic modulus $2.7 \times 105 \mathrm{MPa}$ and Poisson's ratio 0.167 .

The element C3D8 was used for steel beam and anchor in model while C3D8R element for concrete. Two kinds of shear span ratio, 0.3 and 0.5 , were adopted to study the different modes of flexural failure and shearing failure. 3D model was showed as Fig.1

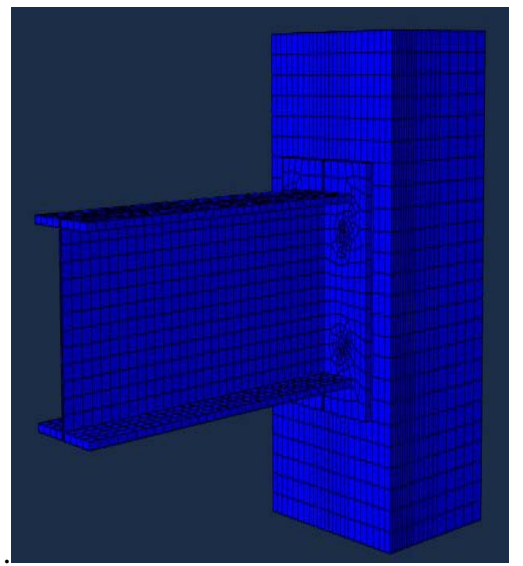

FIGURE I. MODEL DETAIL.

\section{ANALYSIS RESUltS}

In this research the impact of spacing and edge distance on anchorage behavior had been emphasized. The whole analysis was divided into two parts. Firstly, three kinds of edge distance were considered in models with same spacing. Secondly, three kinds of anchor spacing in models with same edge distance were considered as well. All the analytical results had been listed in Table.1.Deflection of steel beam and longitudinal displacement of rebar were shown in Fig.2.

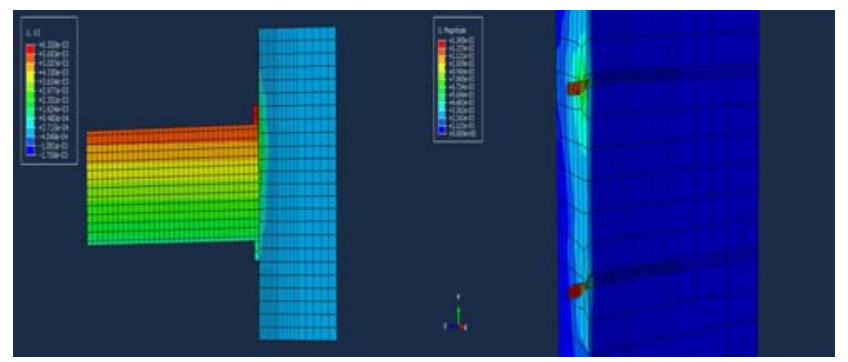

FIGURE II. DEFLECTION OF STEEL BEAM AND LONGITUDINAL DISPLACEMENT OF REBAR.
TABLE 1. EXPERIMENT RESULTS LISTS.

\begin{tabular}{|c|c|c|c|c|}
\hline \multirow{4}{*}{ Parameters } & Number & Yielding & Ultimate & Failure \\
\hline \multirow{2}{*}{$\begin{array}{c}\text { Edge } \\
\text { distance }\end{array}$} & C7S16 & 16.10 & 28.41 & $\begin{array}{c}\text { Steel } \\
\text { tensile }\end{array}$ \\
\cline { 2 - 5 } & C5S16 & 14.90 & 24.77 & $\begin{array}{c}\text { Steel } \\
\text { tensile }\end{array}$ \\
\cline { 2 - 5 } & C10S16 & 15.98 & 28.5 & $\begin{array}{c}\text { Steel } \\
\text { tensile }\end{array}$ \\
\hline \multirow{2}{*}{ spacing } & C12S5 & 17.11 & 24.12 & $\begin{array}{c}\text { Steel } \\
\text { tensile }\end{array}$ \\
\cline { 2 - 5 } & C12S & 16.00 & 25.41 & $\begin{array}{c}\text { Steel } \\
\text { tensile }\end{array}$ \\
\cline { 2 - 5 } & C12S12 & 16.46 & 30.4 & $\begin{array}{c}\text { Steel } \\
\text { tensile }\end{array}$ \\
\hline
\end{tabular}

\section{A. Spacing}

The anchorage mechanism was to transfer the applied force to the concrete that surrounded in anchors. Therefore, the loadbearing concrete area should be large enough to guarantee the individual concrete cone development which means sufficient spacing was required. Otherwise overlapped concrete cones would lead to concrete brittle failure in small spacing. The ideal failure mode was anchor steel failure that was a ductile mode. So the distance had a great influence on the anchorage performance. The anchorage strength had been investigated for three kinds of spacing 5d, 8d and 12d respectively. Three conditions had same embedment depth and edge distance.

Analysis results showed that the yielding strength for three kinds of conditions was almost similar with the peak value $16 \mathrm{KN}$. And surface displacements of each specimen were shown in the Fig.3, and yielding load and ultimate load of all specimens were listed in the table1. The load - displacement curves in Fig. 4 indicated that the curve can be divided into three stages: elastic stage, development stage and falling stage. At the initial stage of loading, strain growth was linear development pattern, and the displacement was small. When the anchor bolt was pulled up to the yield, the tensile strain increased, and the displacement of the anchor bolt was increased with the increase of load. And it began rotating around the tension zone. Meanwhile the crack occurred between the anchor plate and the concrete base surface .With the increasing of ultimate load, the shape of concrete cone in tension zone had been developed fully, finally anchor reached the yield situation and damage. In the three conditions, the spacing of C12S12 had maximum value, and the shape of concrete cone could be fully developed. While for the models C12S5 and C12S8 overlapped concrete cones in final state were found which induce strength loss, therefore the minimum spacing was suggested to the value of $10 \mathrm{~d}$. 


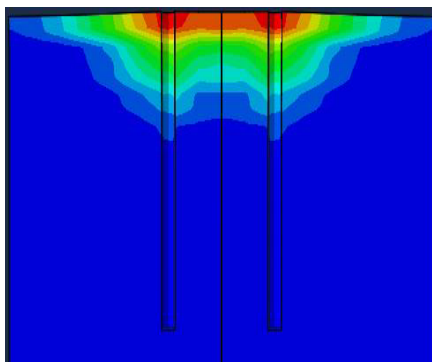

C12S5

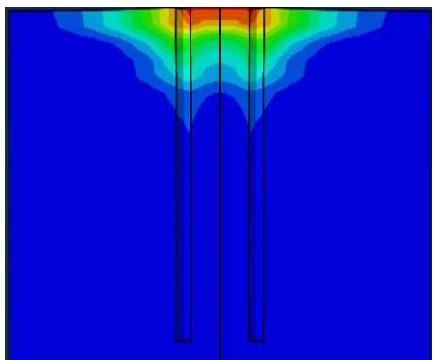

C12S8

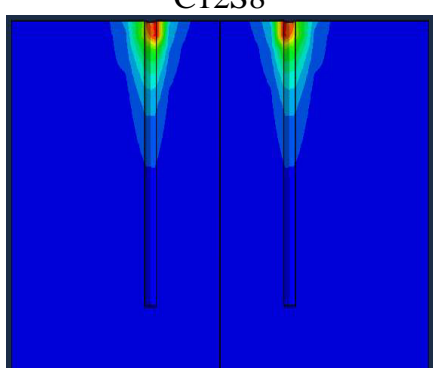

C12S12

FIGURE III. STRESS CONTOUR FOR DIFFERENT SPACING.

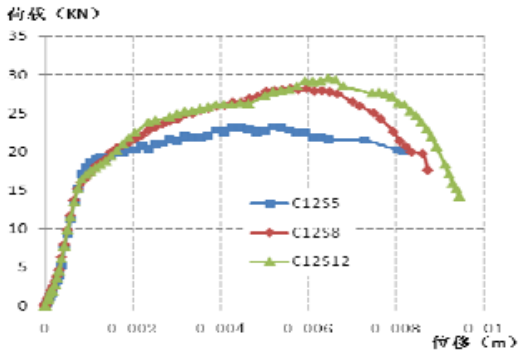

FIGURE IV. COMPARISONS OF LOAD-DISPLACEMENT CURVES.

\section{B. Edge Distance}

This section will study the bearing capacity of anchors under three kinds of edge distance $5 d, 7 d, 10 d$ respectively. In three kinds of conditions embedment depth and spacing are kept to constants. From the figure5, it can be seen that there was no individual concrete cone for anchor in C5S16 which caused the lower bearing capacity than other models. In case of C10S16 edge distance was big enough to form complete concrete cone and the outer edge of cone did not develop beyond the base edge. From the comparison of strength curves in Fig.6, it also could be found that the bearing capacity in 5d edge distance was significantly lower than the rest two cases. So the minimum value of edge distance was advised to $8 \mathrm{~d}$.

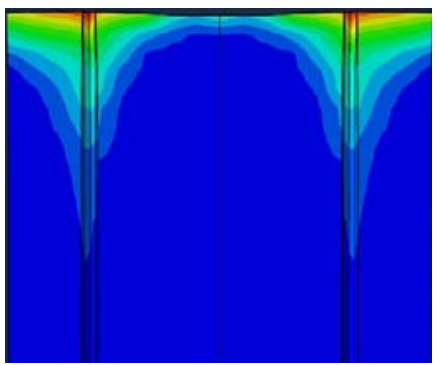

C5S16

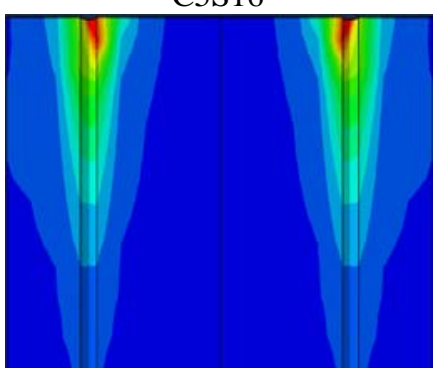

C7S16

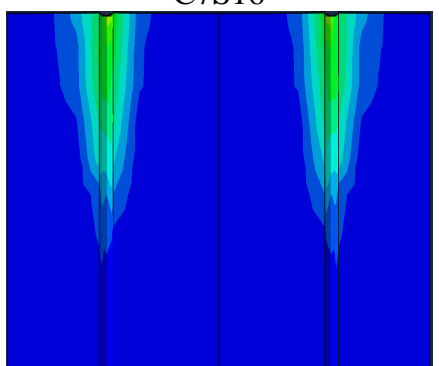

C10S16

FIGURE V. CONCRETE CONE DISPLACEMENT FOR THREE KINDS OF EDGE DISTANCE.

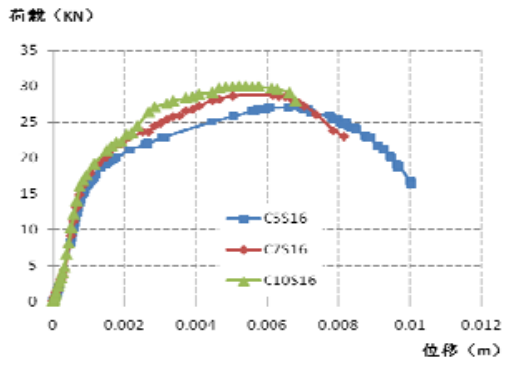

FIGURE VI. COMPARISON OF LOAD-DISPLACEMENT CURVES

According to the Figure7, under the combined moment and shear loading the top row of anchors were subjected to tension while the bottom anchors were in compressive zone. The anchor stress in tensile zone wasn't uniform along embedment depth and the maximum stress occurred in the loaded end of anchor which gradually reduced towards base interior with deeper length. The tensile anchor presented good ductility in ultimate state. 


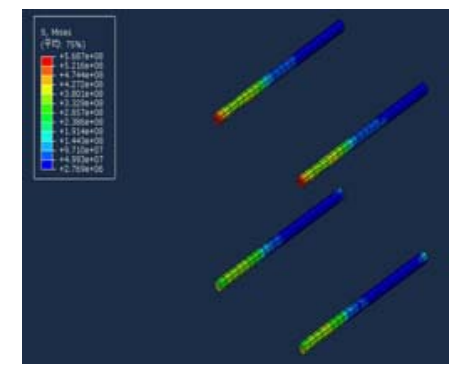

FIGURE VII. ANCHOR STRESS CONTOUR.

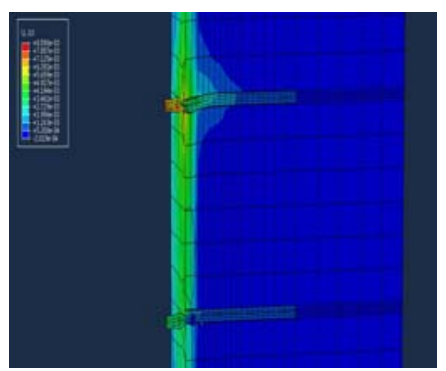

FIGURE VIII. LONGITUDINAL DISPLACEMENT OF REBAR.

The anchor strain near the surface of concrete block showed linear development under initial load and there was no residual strain when the load was totally removed. Information could be learned from Fig.8 that displacement for both base plate and the load ended of anchor was almost little and no visual crack in concrete surface. With the increasing of load, anchor strain began to increase non-linearly and the anchor part near the concrete surface would reach its yield strength and axis deformation had obvious growth. A relative rotation of steel attachment around the toe of steel plate appeared nearly ultimate load, at last the strength of connection was governed by the steel yielding of anchor shank and about $1 / 3$ portion of anchor along the embedment length could reach yielding strength in failure. Concrete cone only occurred near loaded end of anchor.

\section{CONCLUSIONS}

1) Spacing had a great influence on the anchorage performance. Concrete cone overlap was anticipated in spacing of both 5d and 8d and independent concrete cone in spacing 12d and group effect should be considered in anchor design. The minimum value of spacing was suggested to $10 \mathrm{~d}$ in the case of embedment depth 15d.

2) The study on edge distance showed that anchor strength would have reduction in the case of $5 \mathrm{~d}$ because of insufficient area. Longer edge distance could ensure enough concrete area to transfer load, and the load-bearing of concrete area was controlled by the edge of the base material, which could form complete stress cone and performed well in the strength of anchor. Therefore the critical value $8 \mathrm{~d}$ for edge was recommended.

\section{ACKNOWLEDGMENT}

This research was financially supported by Project of Shandong Province Natural Science Foundation Program
(Granted No.ZR2014EL037) and Project of Shandong Province Higher Educational Science and Technology Program (Granted No.J13LG06).

\section{REFERENCES}

[1] Kai Xiang, Zhoudao Lu, Jie Li.Experimental study on the shear bearing capacity of Post-Installed anchor group in concrete structures[J].Journal of Shenyang Jianzhu University (Natural Science).2008,24(6),pp. 986987.

[2] Lei Su, Jie Li, Chemical anchor bolt anchorage group subjected to shearing strength .Journal of Harbin Institute of Technology[J].2009,25(5),pp. 41-43.

[3] Jie Li, Zhoudao Lu , Zhanhong Li.Shear capacity analysis of the concrete post-installed anchors[J].Sichuan Building Science.2007,33(6),pp. 56-57.

[4] Shuguang Zhang, Juanjuan Li .The finite element analysis of tension performance of embedded steel-bars by fasteners in concrete[J].Journal of Changchun Institute of Technology (Natural Science Edition).2010,11(3),pp. 25-28.

[5] Xinlin Wang. Bearing capacity of chemical anchor in small spacing[MS Thesis] .Wuhan: Wuhan University of Science and Technology. 2011,11.

[6] Tiezhu Jiang, Fuquan Xu . Linzhi Wu.Experimental study on tension performance of anchor group[J].Earthquake Resistant Engineering and Retrofitting. 2013,35(5),pp. 109-111.

[7] Yijun Li, ROLF ELIGEHAUSEN. Numerical analysis of quadruple fastenings with bonded anchors[J].2002,99(2): 149-156.

[8] M RODRIGUEZ, DIETER LOTZE, HERMAN L GROSS, ZhANG Yonggang, RICHARD E KLINGNER. Dynamic Behavior of Tensile Anchors to Concrete[J]. 2001,98(4),pp. 511-524.

[9] Yonggang Zhang,RICHARD E.KLINGNER,H.L.GRAVES. Seismic response of multiple-anchor connections to concrete[J]. 2001,98(6),pp. 811-822.

[10] RONALD A.COOK, KONZ, ROBERT.Factors influencing bond strength of adhesive anchors[J].2001,98 ,pp. 1154-1168.

[11] JENNIFER LYNN BURTZ. Behavior and design of grouted anchors loaded in tension including edge and group effects and qualification of engineered group products[D]. University of Florida , Miame,America,2003.

[12] NICOLAS PINOTEAU: International Journal of Adhesion \& Adhesive .2011,31,pp. 851-861.

[13] Changqing Liu.Journal of Harbin Institute of Technology[J].2012,31,pp. 1985-1962.

[14] Yonggang Zhang,RICHARD E.KLINGNER,H.L.GRAVES. Seismic response of multiple-anchor connections to concrete[J]. ACI Structural Journal.2001,98(6),pp. 811-822.

[15] W.FUCHS,ELIGEHAUSEN.Actual tendencies in structural fastening technology[M].Advances in Construction Materials.2007,98(6),pp. 2330 .

[16] RONALD A.COOK,RICHARD E.KLINGNER. Ductile multiple-anchor steel-to-concrete connections[J]. Journal of Structural Engineering.1992,118(6),pp. 1645-1665. 